\title{
Osmotic Adjustment in Roots and Leaves of two Cotton Cultivars with Different Tolerance to Soil Salinity
}

\author{
Tingting Chen, Yong Chen, Xiaolong Wang and Lei Zhang* \\ College of Agriculture, South China Agricultural University, China \\ *Corresponding author: Lei Zhang, College of Agriculture, South China Agricultural University, China
}

\begin{tabular}{|c|c|}
\hline ARTICLE INFO & ABSTRACT \\
\hline $\begin{array}{l}\text { Received: 慧 January 29, } 2019 \\
\text { Published: 慧 February 27, } 2019\end{array}$ & $\begin{array}{l}\text { The object of this study was to analysis the change of organic and inorganic solutes } \\
\text { and their function to Osmotic Adjustment (OA) in the leaves and roots of cotton (Gosspi- } \\
\text { um hirsutum L) subjected to heterogeneous salinity conditions. We grew two cotton culti- }\end{array}$ \\
\hline $\begin{array}{l}\text { Citation: Tingting Chen, Yong Chen, } \\
\text { Xiaolong Wang, Lei Zhang. Osmotic } \\
\text { Adjustment in Roots and Leaves of } \\
\text { two Cotton Cultivars with Different } \\
\text { Tolerance to Soil Salinity. Biomed J } \\
\text { Sci \& Tech Res 15(2)-2019. BJSTR. } \\
\text { MS.ID.002679. } \\
\text { Keywords: Gosspium Hirsutum L; Salt } \\
\text { Stress; Osmotic Adjustment; Toler- } \\
\text { ance; Osmotic Potential }\end{array}$ & 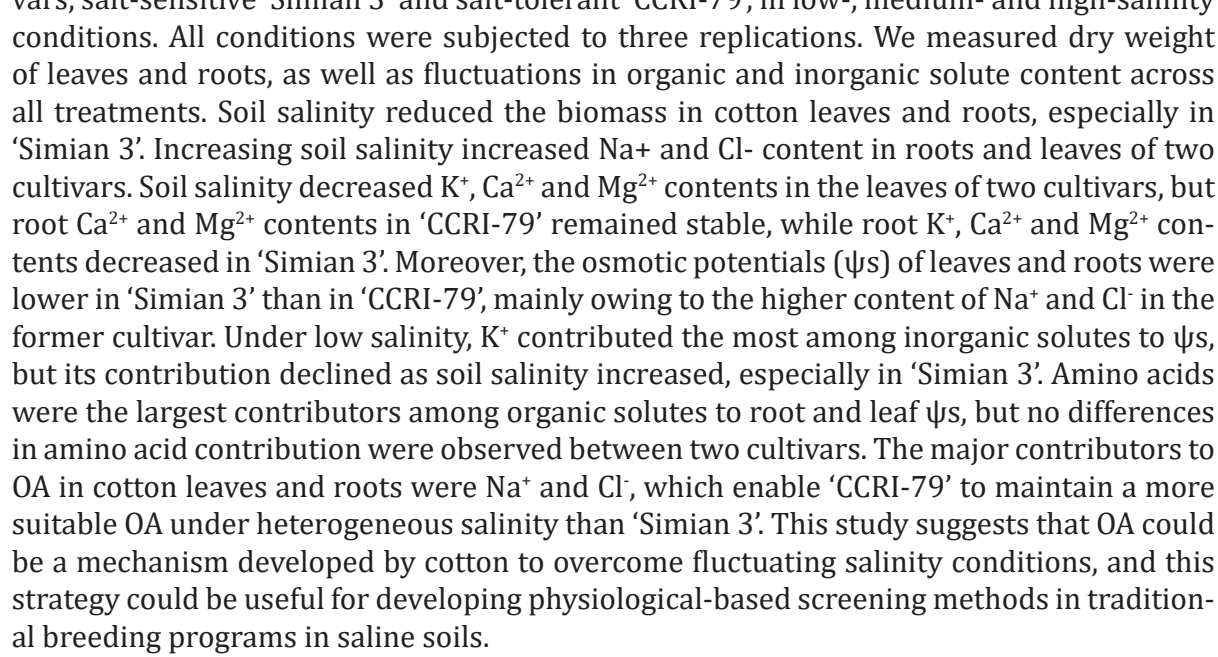 \\
\hline
\end{tabular}

\section{Introduction}

High salt concentrations in soil water impose osmotic and /or ionic stress and result in changed morphological and development patterns and modified physiological and biochemical processes in plants. Salt stress can inhibit plant growth through numerous mechanisms, including low external water potential, ion toxicity and interference with nutrient uptake, particularly $\mathrm{K}^{+}$[1]. Both excess and low salinity levels are a concern; The growth of many salt-sensitive plant species is inhibited by low salinity and excess salt in the soil can reduce osmotic potential to such an extent that crops cannot take up enough water [2]. Thus, finding strategies to address salt stress is a global matter that can ensure agricultural success and sustainable food production. Although the plants display marked differences in their salt tolerance degree, they share a similar salt inclusion strategy to deal with excessive salinity [3]. In this process, the leaf tissues are adapted to accumulate large amounts of saline ions, sometimes greater than those surrounding roots.

Such adaptive mechanism is crucial to generate a water potential gradient along root-shoot in order to maintain water flux throughout plant [4]. Most salt stress in plants is caused by $\mathrm{Na}$ salts (particularly $\mathrm{NaCl}$ ) and take two distinct forms: water stress and ionic stress [5]. Salt stress refers to the inhibition of water absorption that occurs when roots uptake high concentrations of $\mathrm{Na}^{+}$and $\mathrm{Cl}^{-}$. Once these ions accumulate in the plant, they can negatively influence nutrient uptake through competitive interaction with other ions or by affecting membrane selectivity. For example, high $\mathrm{Na}^{+}$concentrations frequently induce $\mathrm{Ca}^{2+}$ and $\mathrm{K}^{+}$deficiencies, resulting in impaired metabolic processes and lowered photosynthetic efficiency [6,7]. The adaptation to salinity is accompanied by accumulation of organic osmotically active compounds called osmolytes as a result of alterations in 
intermediary and secondary metabolism of nitrogen or of carbon. This phenomenon, known as Osmotic Adjustment (OA), is an important component of salinity tolerance mechanisms in plants $[8,9]$. According to Blum et al. OA is usually defined as a decrease in cell sap osmotic potential resulting from a net increase in intracellular solutes rather than from a loss of cell water.

This salinity tolerance mechanism activates in response to decreased water potential in the root medium; a net accumulation of organic and/or inorganic solutes decrease osmotic potential [10], which in turn pulls water into the cell and allows the plant to maintain turgor [11,12]. More specifically, OA may operate through the accretion of solutes such as electrolytes (e.g. $\mathrm{Ca}^{2+}, \mathrm{Cl}^{-}, \mathrm{K}^{+}, \mathrm{Ca}^{2+}$, $\mathrm{K}^{+}$), proline, free amino acids, sugars, polyphenols, and glycine betaine $[13,14]$. Through their influence on osmotic balance, these solutes exert a protective effect on major plant enzymes when electrolyte concentrations are high in the cytoplasm [15]. Although there is considerable interest in plant physiological responses to salinity, most of the research examining this topic subjected plants to uniform conditions, with only one concentration of $\mathrm{NaCl}$. However, saline soils are inherently patchy; a field could contain areas ranging from low salinity to several times more saline than seawater [16]. Thus, we currently have limited understanding of plant physiological responses to heterogeneous soil salinity. We require insights into how shoot ion concentrations are regulated by the saline portions of heterogeneous root zones. Cotton (Gosspium hirsutum L.) is a suitable crop for investigating such questions. One of the most economically important crops in China, cotton is classified as salt-tolerant, but this tolerance is limited, varying across cultivar and developmental stage [17]. Several studies have assessed the effect of salt stress on cotton germination, vegetative growth, or yield under uniform salinity $[18,19]$, but not under heterogeneous salinity. Therefore, our aims were first to evaluate the influence of heterogeneous salinity on plant growth, osmotic potential, and Osmotic Adjustment. Next, we compared the Osmotic Adjustment of salt-sensitive versus salt-tolerant cotton cultivars, via measuring solute concentrations and distributions. Our results will complement existing knowledge of cotton physiology under uniform salinity and improve our understanding of how field soil conditions affect cotton growth.

\section{Materials and Methods}

\section{Experimental Design}

The field experiments were conducted using two cotton cultivars that differed significantly in salt tolerance. Salt-tolerant 'CCRI-79' and salt-sensitive 'Simian 3' were grown in Dafeng Basic Seed Farm located in Dafeng $\left(33^{\circ} 20^{\prime} \mathrm{N}, 120^{\circ} 46^{\prime} \mathrm{E}\right)$, Jiangsu during 2013 and 2014. This farm is state-owned, and no specific permissions were required to use this farm for the experiments described herein. Additionally, the field studies did not involve any protected species. We selected three soils that were similar in texture and nutrient composition, but differed in salinity (low, medium, or high). Soil conductivities were 1.15 (low soil salinity, LS), 6.00 (medium soil salinity, MS), and $11.46 \mathrm{dS} \mathrm{m}^{-1}$ (high soil salinity, HS). The LS and MS soils had been planted with rice for the previous 5 and 2 years, respectively, in contrast to the HS soil, which was not planted with rice or cotton before the experiment.
Cotton seeds were directly sown in the field at a density of 45,000 $\mathrm{hm}^{-2}$ on 28 Apr. 2013 and 4 May 2014. Three replicates were assigned randomly for each salinity treatment. Nitrogen (N)fertilizer ( $240 \mathrm{~kg} \mathrm{~N} \mathrm{ha}^{-1}$ ) was sequentially added to the field; $40 \%$ as the base and $60 \%$ during flowering and boll formation. The amount of P used as base fertilizer was $120 \mathrm{~kg}$ P205 ha-1. The amount of $\mathrm{K}$-fertilizer was $120 \mathrm{~kg} \mathrm{~K}_{2} \mathrm{O} \mathrm{ha}{ }^{-1}$, at a ratio of $50 \%$ base fertilizer to $50 \%$ during flowering and boll formation. Conventional weed and insect control measures were applied as needed.

\section{Measurement of Plant Dry Weight}

The cotton plants were cut at the soil surface and separated into leaves, stems and roots during flowering and boll-forming stages. The root samples were washed with tap water on a 0.5$\mathrm{mm}$ mesh screen. Fresh weight of all plant parts was immediately determined upon sampling. Dry Weight (DW) was measured after drying for $48 \mathrm{~h}$ at $70 \mathrm{oC}$. The remaining material from roots, leaves, and stems were collected and immediately frozen in liquid nitrogen, then lyophilized to determine inorganic and organic solute concentrations.

\section{Measurement of Solute Contributions to Osmotic Adjustment}

Root and leaf blade samples stored in plastic bags at $-20^{\circ} \mathrm{C}$ were thawed, pressed in a hydraulic press, and centrifuged at 2,500 $\mathrm{g}$ for $20 \mathrm{~min}$. The supernatant was used as 'cellular sap'. The osmotic potential $(\psi s)$ in the combined supernatants of three replicates was determined with a vapour pressure osmometer (model 5500; Wescor, Logan, UT, USA). Tissue organic and inorganic solute concentrations were converted to osmolality based on tissue water content. Contributions of leaf and root $\psi$ s for each measured solute concentration were calculated according to the Van 't Hoff equation (Nobel, 1991), which applies strictly to ideal dilute solutions: $\psi \mathrm{s}=$ -nRT, where $\mathrm{n}=$ ossmol $(\mathrm{g} \mathrm{H} 2 \mathrm{O})^{-1}, \mathrm{R}=8.314 \times 10-5 \mathrm{~m}^{-3}$ bar $\mathrm{mol}^{-1} \mathrm{~K}^{-1}$ and $\mathrm{T}=298.2 \mathrm{~K}$. For $\mathrm{n}$, the values were expressed as $\mu \mathrm{mol} \mathrm{mL}^{-1}$.

\section{Determination of Organic Solutes}

Free proline content was analysed using previously published methods [20]. Total Free Amino Acid (FAA) content was estimated as described by Mukherjee and Choudhuri [21] with some modifications. Fresh root samples conserved in liquid $\mathrm{N}$ were extracted with $10 \mathrm{~mL}$ of $6 \%$ trichloroacetic acid. Four millilitres of each extract was mixed with $2 \mathrm{~mL}$ of $2 \%$ dinitrophenylhydrazine, then with one drop of $10 \%$ thiourea prepared in $70 \%$ aqueous ethanol. The resulting reaction mixture was refluxed for $15 \mathrm{~min}$ using a water bath and then immersed into an ice bath until cooled to around $0^{\circ} \mathrm{C}$. Next, $5 \mathrm{~mL}$ of $80 \%(\mathrm{v} / \mathrm{v}) \mathrm{H}_{2} \mathrm{SO}_{4}$ was added. The absorbance was recorded at $530 \mathrm{~nm}$ and FAA concentrations were calculated from a standard curve, plotted with known leucine concentrations.

Total Soluble Sugars (TSS) were extracted from $50 \mathrm{mg}$ of lyophilized powder using a previously described method [22]. The extractions were then analysed using an Agilent Hewlett-Packard 5890 series II gas chromatograph (Agilent Technologies, Santa Clara, CA, USA), equipped with a flame ionization detection system and an HP-5MS capillary column. Injector temperature was set to 
$250^{\circ} \mathrm{C}$. The temperature of the capillary column was programmed to increase from $180^{\circ} \mathrm{C}$ to $300^{\circ} \mathrm{C}$ at a rate of $5^{\circ} \mathrm{C}$ per min. We identified individual carbohydrates using relative retention times (i.e. comparing the retention times of the standard with the carbohydrates identified earlier using gas chromatography-mass spectrometry).

\section{Determination of Inorganic Solutes}

The concentrations of $\mathrm{Ca}, \mathrm{Mg}, \mathrm{K}$ and $\mathrm{Na}$ were analysed in subsamples of finely ground (with a mill grinder) dried plant materials. Approximately $0.5 \mathrm{~g}$ of the ground plant samples were placed into digesting tubes, to which $10 \mathrm{~mL}$ of concentrated nitric acid and $3 \mathrm{~mL}$ of perchlorate acid were added. All samples were soaked for $12 \mathrm{~h}$ and then burned at $300^{\circ} \mathrm{C}$ for $3 \mathrm{~h}$. The residue was transferred to a $50-\mathrm{mL}$ volumetric flask, which was filled with distilled water. The cation content was then measured using an atomic absorption spectrophotometer (TAS-986; Persee, Beijing, China) [23]. To determine $\mathrm{Cl}^{-}$content, leaf samples $(0.1$ g) were extracted in $10 \mathrm{~mL}$ of distilled water via heating at $80^{\circ} \mathrm{C}$

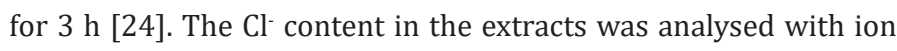
chromatography (DX-300; Sunnyvale, CA, USA) [25].

\section{Statistical Analysis}

The experimental design was completely randomized, including two cotton cultivars and three salinity levels. OriginPro 9.0 was used for data processing and figures. An ANOVA was performed using SPSS version 17.0, and the means were separated with the Least Significant Difference (LSD) test. Differences were considered significant at $\mathrm{P}<0.05$. In all figures, data are represented as means \pm standard errors.

\section{Results}

\section{Plant Growth}

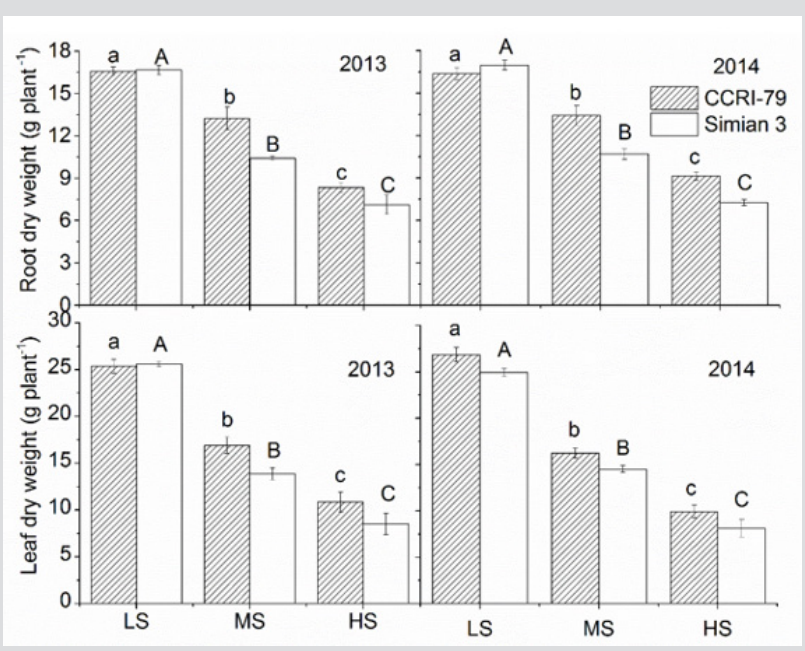

Figure 1: Effects of soil salinity on leaf and root dry weights of two cotton cultivars at flowering and boll-forming stages, during 2013 and 2014. LS: low soil salinity; MS: medium soil salinity; HS: high soil salinity. Vertical bars represent \pm standard error $(n=3)$. Bars labelled with different lowercase letters on open-square bars or uppercase letters on closed-square bars represent significant differences $(\mathrm{P}<0.05)$.

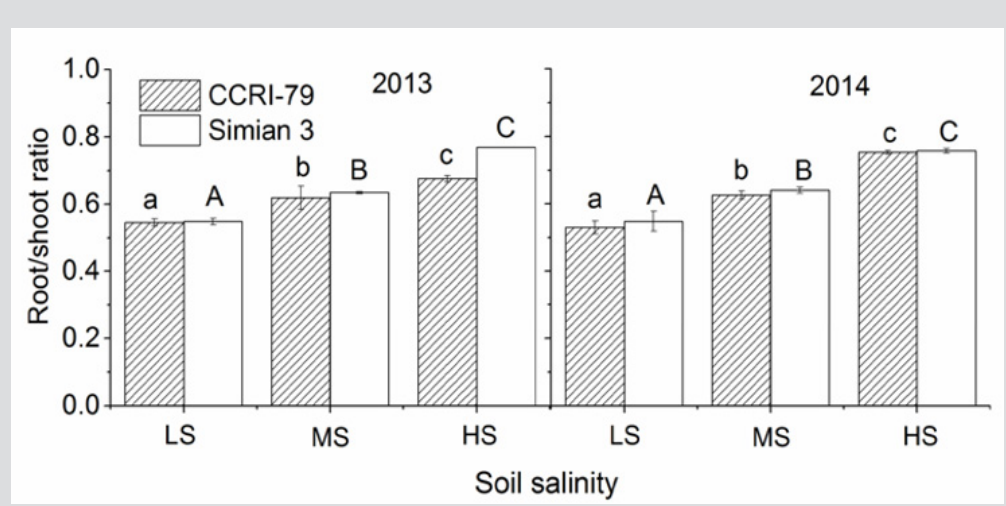

Figure 2: Effects of soil salinity on the root/shoot ratio of two cotton cultivars at flowering and boll-forming stages, during 2013 and 2014. LS: low soil salinity; MS: medium soil salinity; HS: high soil salinity. Vertical bars represent \pm standard error $(n=3)$. Bars labelled with different lowercase letters on open-square bars or uppercase letters on closed-square bars represent significant differences $(\mathrm{P}<0.05)$. 
At boll forming and opening stages, the root and leaf biomass (DW) of both 'CCRI-79' and 'Simian 3' significantly decreased compared with the control (Figure 1). The highest leaf and root DW occurred in LS. Soil salinity inhibited leaf growth more than root growth, and the proportion of root DW to leaf DW increased with increasing soil salinity (Figure 2). 'CCRI-79' experienced less growth inhibition under saline conditions than 'Simian 3'. Importantly, all plants appeared healthy at boll forming and opening stages. Despite their small size in HS, all plants were able to flower (data not shown).

\section{Ion Concentrations}

In saline soils, the leaves and roots of both cultivars had higher $\mathrm{Na}^{+}$and $\mathrm{Cl}^{-}$concentrations due to nonspecific ion uptake and/or membrane leakage. As soil salinity increased, $\mathrm{Na}^{+}$and $\mathrm{Cl}^{-}$further increased in both root and leaf at the boll forming and opening stages, with 'Simian 3' experiencing a greater increase than 'CCRI79' (Figure 3). Across all salinity levels, $\mathrm{Na}^{+}$concentrations in leaves were higher than in the roots of both cultivars, indicating that neither cultivar could prevent $\mathrm{Na}^{+}$transportation from the roots to leaves. Chlorine ions showed a similar distribution pattern to $\mathrm{Na}^{+}$. As soil salinity increased, $\mathrm{K}^{+}$concentrations in the leaves and roots of both cultivars significantly decreased, with 'Simian 3' exhibiting significantly lower concentrations than 'CCRI-79' (Figure 4A). Magnesium ion concentrations also decreased with increasing soil salinity in both cultivars (Figure 4B), but only in leaves. Root $\mathrm{Mg}^{2+}$ concentrations significantly decreased in 'Simian 3' and remained stable in 'CCRI-79'. In general, regardless of salinity conditions, root $\mathrm{Mg}^{2+}$ concentrations were always lower in 'Simian 3' than in 'CCRI79'. The response of root and leaf $\mathrm{Ca}^{2+}$ concentrations was very similar to $\mathrm{Mg}^{2+}$ (Figure 4C).
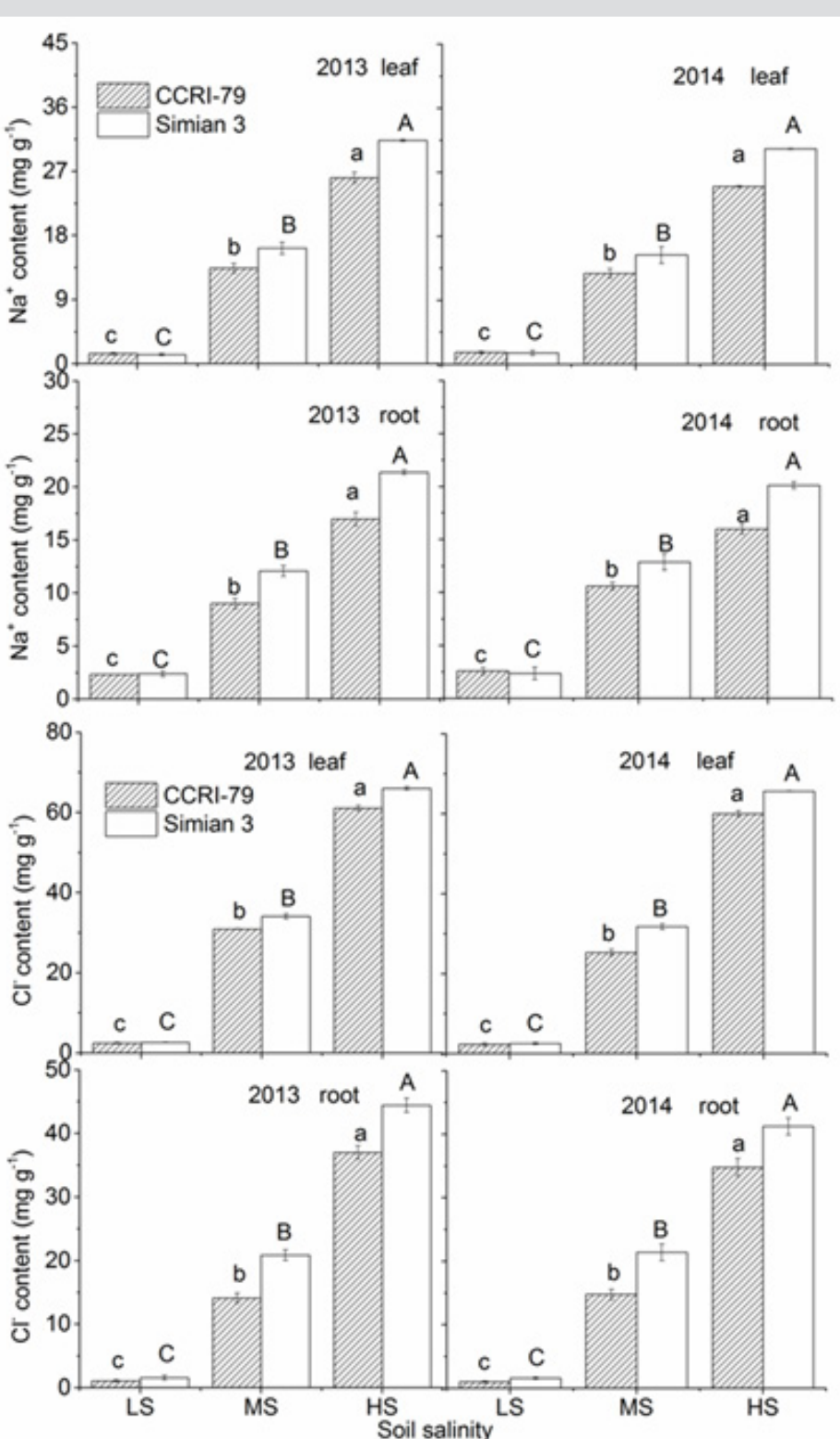

Figure 3: Effects of soil salinity on leaf and root $\mathrm{Na}+$ and $\mathrm{Cl}$ - concentrations in two cotton cultivars at flowering and bollforming stages, during 2013 and 2014. LS: low soil salinity; MS: medium soil salinity; HS: high soil salinity. Vertical bars represent \pm standard error $(n=3)$. Bars labelled with different lowercase letters on open-square bars or uppercase letters on closed-square bars represent significant differences $(\mathrm{P}<0.05)$. 

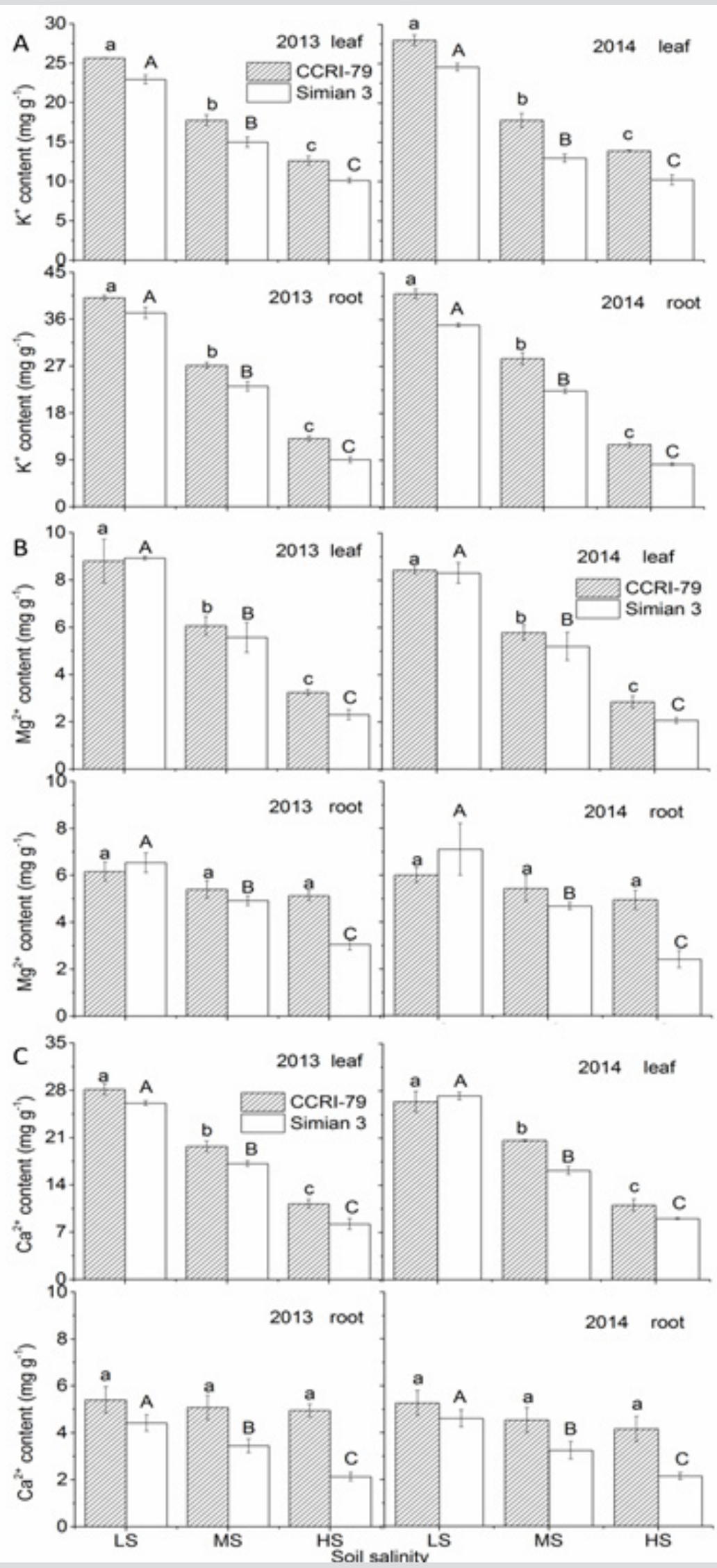

Figure 4: Effects of soil salinity on leaf and root $\mathrm{K}^{+}, \mathrm{Ca}^{2+}$, and $\mathrm{Mg}^{2+}$ concentrations in two cotton cultivars at flowering and boll-forming stages, during 2013 and 2014. LS: low soil salinity; MS: medium soil salinity; HS: high soil salinity. Vertical bars represent \pm standard error $(n=3)$. Bars labelled with different lowercase letters on open-square bars or uppercase letters on closed-square bars represent significant differences $(\mathrm{P}<0.05)$. 


\section{Organic Solute Accumulations}

Salinity induced a marked increase in 'Simian 3' root proline concentrations, whereas no significant changes were observed in 'CCRI-79' (Figure 5A). However, proline concentrations increased with increasing soil salinity in the leaves of both cultivars, although the change was less dramatic in 'CCRI-79'. With increasing soil salinity, FAA accumulation in roots and leaves increased significantly, being more pronounced for 'Simian 3' than for 'CCRI79' (Figure 5B). In contrast to FAA, TSS concentrations in the leaves and roots of both cultivars were not significantly changed by soil salinity (Figure 5C).

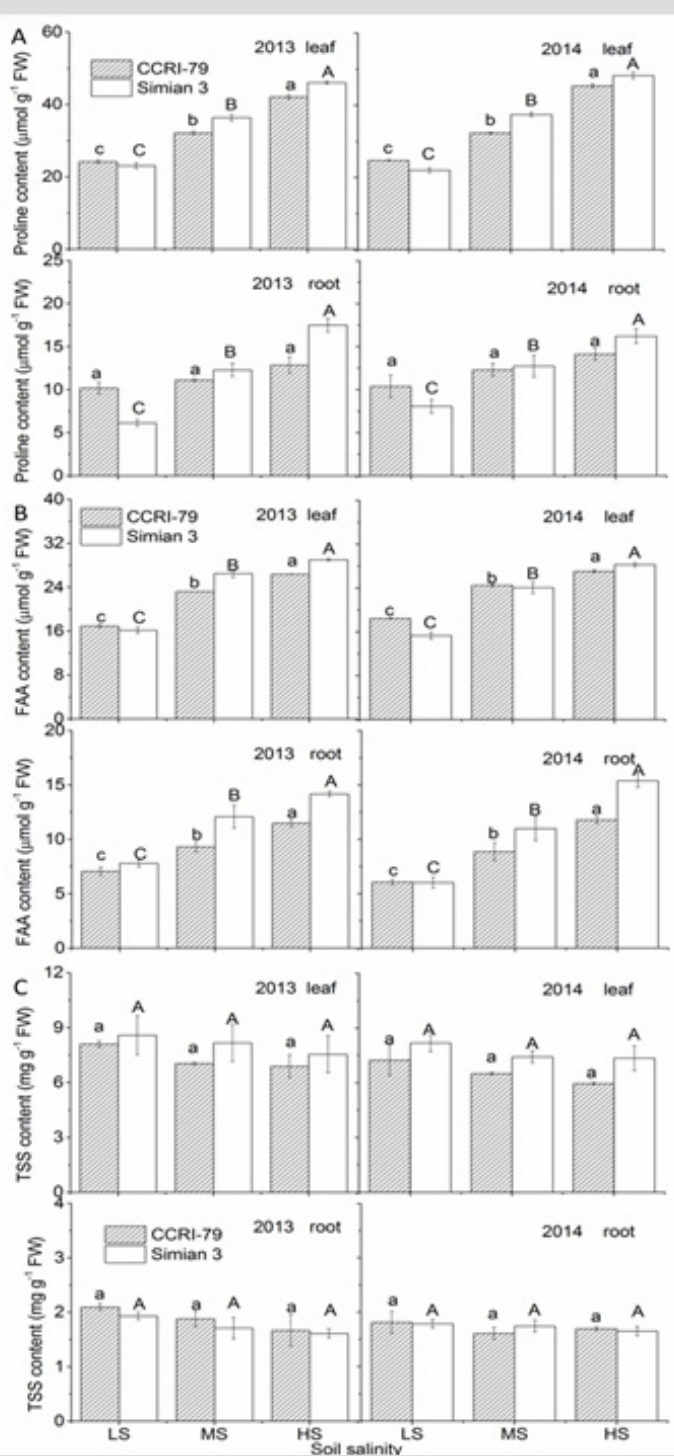

Figure 5: Effects of soil salinity on leaf and root proline, free amino acid, and total soluble sugar contents in two cotton cultivars at flowering and boll-forming stages, during 2013 and 2014. LS: low soil salinity; MS: medium soil salinity; HS: high soil salinity. Vertical bars represent \pm standard error $(n=3)$. Bars labelled with different lowercase letters on open-square bars or uppercase letters on closed-square bars represent significant differences $(\mathrm{P}<0.05)$.

\section{Osmotic Potential and the Contribution of Individual Solutes to OA}

The $\psi$ s decreased in leaves and roots of both cultivars with increasing soil salinity. The $\psi \mathrm{s}$ was approximately two times lower in the leaves than in the roots and was higher in 'CCRI-79' than in 'Simian 3' (Figure 6). The contributions of organic and inorganic solutes to $\psi$ s depended on plant organ and genotype (Table 1). The contribution of $\mathrm{Na}^{+}$and $\mathrm{Cl}^{-}$in leaf and root $\psi \mathrm{s}$ increased with increasing soil salinity, especially in 'Simian 3'. Overall, $\mathrm{Na}^{+}$and $\mathrm{Cl}^{-}$ contributions to root $\psi \mathrm{s}$ were greater than to leaf $\psi \mathrm{s}$. Under LS, $\mathrm{K}^{+}$and $\mathrm{Mg}^{2+}$ were the major contributors to $\psi \mathrm{s}$ in roots, whereas
$\mathrm{K}^{+}$and $\mathrm{Ca}^{2+}$ were the major contributors to $\psi \mathrm{s}$ in leaves. With increasing soil salinity, $\mathrm{K}^{+}$and $\mathrm{Ca}^{2+}$ contributions to leaf and root $\psi \mathrm{s}$ decreased in both cultivars. However, $\mathrm{Mg}^{2+}$ contributions increased to leaf $\psi \mathrm{s}$ and decreased to root $\psi \mathrm{s}$ in both cultivars. Overall, $\mathrm{Ca}^{2+}$ and $\mathrm{Mg}^{2+}$ contributions were much smaller than $\mathrm{K}^{+}$, which was the primary inorganic solute in the control treatment. As soil salinity increased, however, $\mathrm{K}^{+}$contribution to leaf $\psi \mathrm{s}$ in the salt-sensitive and salt-resistant cultivars respectively decreased by about $62.67 \%$ and $92.73 \%$ during 2013, and by $72.06 \%$ and $77.82 \%$ during 2014 . Additionally, $\mathrm{K}^{+}$contribution to root $\psi \mathrm{s}$ in the salt-sensitive and saltresistant cultivars respectively decreased by $62.34 \%$ and $68.81 \%$ during 2013, and by $66.04 \%$ and $85.39 \%$ during 2014 . 


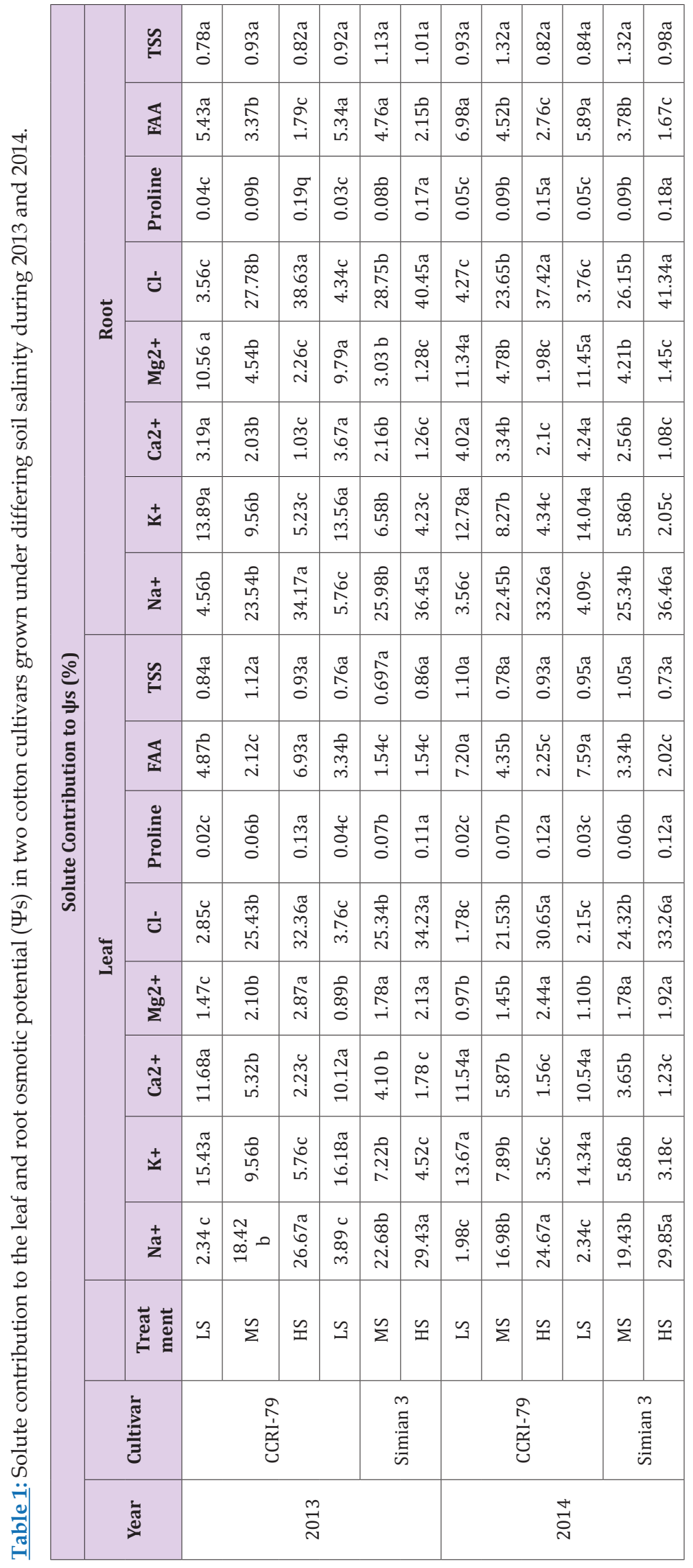




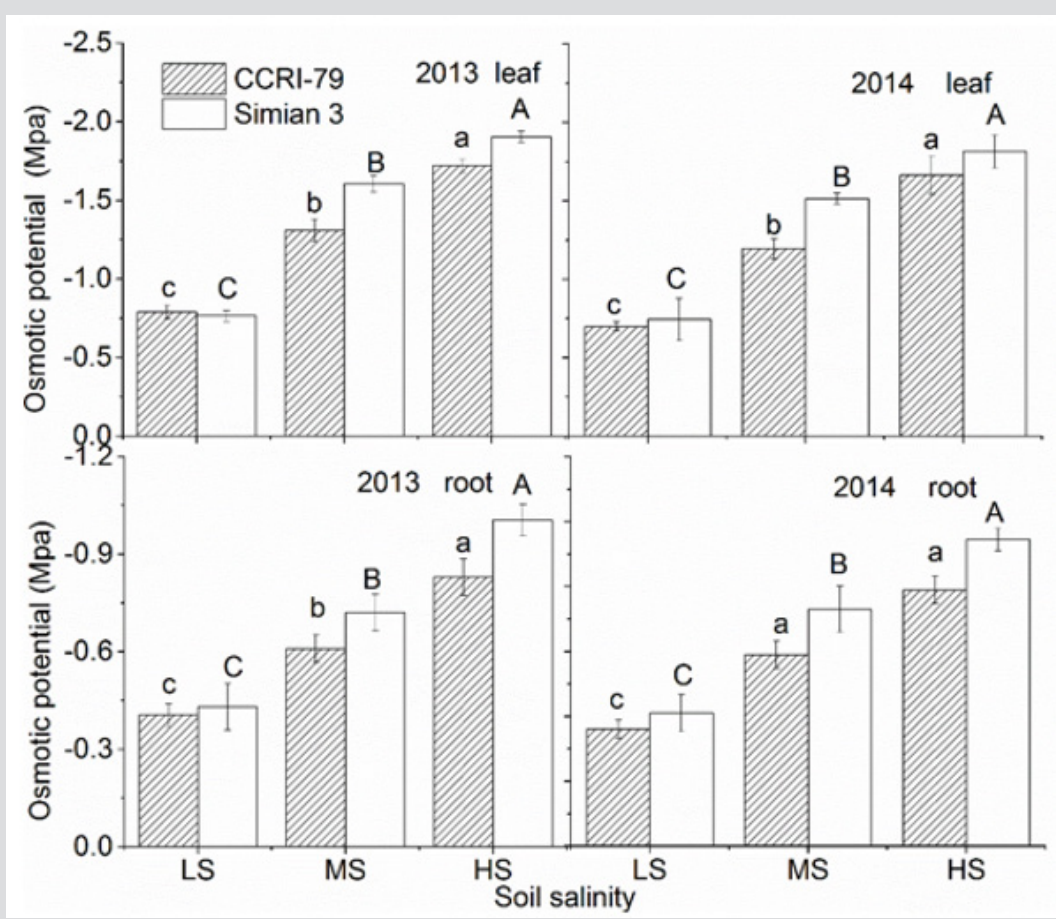

Figure 6: Effects of soil salinity on leaf and root osmotic potential ( $\psi \mathrm{s})$ of two cotton cultivars at flowering and boll-forming stages, during 2013 and 2014. LS: low soil salinity; MS: medium soil salinity; HS: high soil salinity. Vertical bars represent \pm standard error $(n=3)$. Bars labelled with different lowercase letters on open-square bars or uppercase letters on closed-square bars represent significant differences $(\mathrm{P}<0.05) . \mathrm{s}$

The primary organic solute contributing to $\psi$ s was FAA. No difference in FAA contribution was observed between the two cultivars. Under LS, FAA contribution to leaf $\psi \mathrm{s}$ was about $6.50 \%$ (in 'CCRI-79') and 7.20\% (in 'Simian 3') during 2013, and 6.93\% (in 'CCRI-79') and 7.59\% (in 'Simian 3') during 2014. Under HS, these values decreased to about $2.12 \%$ (in 'CCRI-79') and $2.25 \%$ (in 'Simian 3') during 2013, and 1.54\% (in 'CCRI-79') and 2.02\% (in 'Simian 3') during 2014. In contrast, proline contributions to leaf and root $\psi \mathrm{s}$ increased with increasing soil salinity. However, the absolute contribution of proline was the smallest among organic solutes, suggesting that it does not play a large role in cotton OA. In addition, TSS contribution to leaf and root $\psi$ s did not change with increasing soil salinity and did not differ across cultivars.

\section{Discussion}

\section{Salt Stress Reduces Cotton Biomass}

Our results demonstrated that increased soil salinity significantly reduced cotton growth, in agreement with previous research [26]. This negative outcome must be due to the toxic effects of $\mathrm{Na}^{+}$and $\mathrm{Cl}^{-}$on nutrition uptake. We also observed that leaf growth was inhibited by soil salinity levels more than root growth (Figure 1), again confirming previous results in cotton [27] and other crops [28] showing an increased root/shoot ratio under highly saline conditions. Taken together, the results of this and previous research suggest that increased root/shoot ratio is an adaptation allowing for more efficient water and nutrient uptake under salt stress [29]. Finally, heterogeneous salinity had a weaker influence on root and leaf biomass in the salt-resistant cultivar than in the salt-sensitive cultivar. As will be discussed, we believe the increased tolerance of 'CCRI-79' may be caused by differences in the ability of the two cultivars to restrict toxic ion accumulation.

\section{The Role of Inorganic Solutes in Salt Tolerance Mechanisms}

In some species, $\mathrm{Na}^{+}$retention in roots is a convenient saltresistance mechanism, but this does not appear to be the case in cotton. Instead, we found that the salt-tolerant cultivar exhibited lower $\mathrm{Na}^{+}$concentrations in both roots and leaves than the saltsensitive cultivar. These results can be explained by a lower unidirectional $\mathrm{Na}^{+}$influx through the roots of the salt-tolerant cultivar, like what has been shown in Thellungiella halophile and likely also decreased $\mathrm{Na}^{+}$transport to the leaves. In comparison with 'Simian 3', 'CCRI-79' probably possesses more effective mechanisms to restrict $\mathrm{Na}^{+}$absorption by roots and transport to leaves, thus minimizing the toxic effects of excess $\mathrm{Na}^{+}$on physiological processes.

In contrast to the proposed mechanisms of $\mathrm{Na}^{+}$reduction, the reduction of $\mathrm{K}^{+}$concentrations in roots and leaves may be due to a down-regulation of the genes involved in $\mathrm{K}^{+}$transport, as well as to increases in salt-induced plasma membrane damages, which allow $\mathrm{K}^{+}$to leave the plant and be reabsorbed by the soil. The patterns we observed in $\mathrm{K}^{+}$concentrations are consistent with the results of Zhong and Lauchli [30] who found that $150 \mathrm{~mol} \mathrm{~m}-3 \mathrm{NaCl}$ greatly reduced the deposition rates of $\mathrm{K}^{+}$in cotton roots. Alternatively, the salt-induced decrease in leaf and root $\mathrm{K}^{+}$concentrations may be attributed to $\mathrm{K}^{+}$competition with $\mathrm{Na}^{+}$on the root plasma membrane, as suggested by Aslam et al. [31]. If true, then the salt-tolerant cotton cultivar in this study may possess a $\mathrm{K} / \mathrm{Na}$ discrimination mechanism similar to what has been reported for wheat (Gorham, 1994). Calcium ions are widely known to be critical in regulating 
the passive entry of $\mathrm{Na}^{+}$and in $\mathrm{K}^{+} / \mathrm{Na}^{+}$selectivity (Greenway \& Munns, 1983), In our study, $\mathrm{Ca}^{2+}$ and $\mathrm{Mg}^{2+}$ concentrations decreased in the leaves of both cultivars, but not in the roots of 'CCRI-79'.

Thus, the negligible effect of soil salinity on root growth in 'CCRI$79^{\prime}$ may be due to the maintenance of root $\mathrm{Ca}^{2+}$ concentrations, which guarantee membrane integrity and regulate the rate of cellular division in roots. Our findings corroborate a previous study that performed a similar salt-stress experiment on cotton [32]. In our study, the main inorganic ions involved in OA under salt-free conditions were $\mathrm{K}^{+}$, followed by $\mathrm{Ca}^{2+}$ and $\mathrm{Mg}^{2+}$. However, as soil salinity increased, $\mathrm{Na}^{+}$and $\mathrm{Cl}^{-}$contributions to $\mathrm{OA}$ became predominant. We also observed that the increase in $\mathrm{Na}^{+}$and $\mathrm{Cl}$ contributions to root $\psi$ s of salt-stressed plants was higher than to leaf $\psi \mathrm{s}$. This pattern is easily explained by research showing that a significant amount of $\mathrm{Na}^{+}$and $\mathrm{Cl}^{-}$may be retained in the stem and leaf [33], so increases in these organs would not be as dramatic. Furthermore, $\mathrm{Na}^{+}$and $\mathrm{Cl}^{-}$contributions to $\psi \mathrm{s}$ were higher in the salt-sensitive cultivar, probably a factor in its stunted growth under salt stress [33].

Thus, our data indicate that in salt-stressed cotton plants, $\mathrm{OA}$ is ensured mainly by $\mathrm{Na}^{+}$and $\mathrm{Cl}^{-}$, particularly in the leaves. This outcome is consistent with recent observations of $\mathrm{Na}^{+}$and $\mathrm{Cl}^{-}$participation in the $\mathrm{OA}$ of salt-treated Atriplex nummularia leaves [34]. Although we also demonstrated that $\mathrm{K}^{+}$contributed prominently to OA under low-salinity, but not high-salinity, conditions (especially in 'Simian 3'), we currently know little of the mechanisms underlying its influence on $\mathrm{OA}$ in cotton tissue. It is critical to explore the physiological relevance of fluctuations in $\mathrm{K}^{+}$ contribution to $\mathrm{OA}$, as the ion is thought to play a central role in plant salinity tolerance.

\section{The Role of Organic Solutes in Salt Tolerance Mechanisms}

Another major player in the OA of salt-stressed cotton was FAA, the main organic solute contributing to $\psi$ s. Compared to the inorganic solutes, however, FAA's role was minor, as indicated by their low overall contribution to $\mathrm{OA}$ whether in control or saltstressed conditions. The second most prominent organic-solute contributor to OA was TSS. Like FAA, no difference was observed in TSS contribution to leaf and root $\psi$ s under salt stress. Our results contradict reports suggesting that soluble sugars are a major part of full-turgor maintenance in salt-stressed cotton [35], as well as a part of the OA in Crithmum spicatum and C. maritimum [36]. In most plant species (including several glycophytes), proline is considered a non-toxic osmolyte preferentially located in the cytoplasm, or an enzyme protectant [37]. Salinity-induced proline accumulation is well documented, as is the positive correlation between proline content and salt tolerance [38].

However, the role of proline in salt-stressed plants remains vigorously debated [39]. Our experimental evidence showed that proline is not involved in OA of salt-stressed cotton. Importantly, proline contents were higher in the leaves and roots of 'Simian 3' than in 'CCRI-70'. However, we wish to emphasize that under LS, we observed a significant difference in root proline concentrations between the two cotton cultivars, while no significant difference was recorded for $\psi \mathrm{s}$. Moreover, the drastic increase of proline content in the roots of 'Simian 3' under MS was not accompanied by any increase in $\psi$ s. Thus, we suggest that proline is probably associated with separate stress-response functions in plants subjected to excess salinity. Similar results have been reported for other species [39].

\section{Differing Responses of Salt-Sensitive and Salt-Tolerant Cultivars}

Leaf and root $\psi$ s were always lower in the salt-sensitive cultivar, suggesting that increasing $\psi \mathrm{s}$ may not be a reliable measure of $\mathrm{OA}$ and is unrelated to salt tolerance. In our study, the larger $\psi$ s decrease in 'Simian 3' was mainly due to higher $\mathrm{Na}^{+}$and $\mathrm{Cl}^{-}$accumulation. As a result, $\mathrm{Na}^{+}$and $\mathrm{Cl}^{-}$concentrations may have exceeded the amount needed for $\mathrm{OA}$, negatively affecting development and growth [40-43]. Therefore, we suggest that the mechanism behind salt tolerance in 'CCRI-79' is the ability to maintain an OA in the cytoplasm that is suitable for cellular metabolism and plant growth under heterogeneous, salt-stress conditions. Osmotic Adjustment acts to exclude $\mathrm{Na}^{+}$and $\mathrm{Cl}$, allowing the plant to physiologically resist salt stress.

\section{Conclusion}

The accumulation of $\mathrm{Na}^{+}$and $\mathrm{Cl}^{-}$was the primary mechanism behind Osmotic Adjustment of root and leaves in two cotton cultivars under heterogeneous salinity, while the contribution of proline, FAA and TSS appeared less important. In addition, compared with the salt-sensitive cultivar, the salt-tolerant cultivar was able to maintain a more suitable osmotic potential in leaves and roots under salt stress, allowing it to make necessary Osmotic Adjustments that facilitate growth in high-salinity conditions. Although more studies are needed to clarify the mechanisms involved in plant adaptive responses to variation in soil salt content, this study provides an integrated approach that demonstrates remarkable contrasts in the $\mathrm{OA}$ of cotton roots and leaves under long-term conditions of heterogeneous salinity.

\section{Acknowledgement}

This work was supported by the National Natural Science Foundation of China [31301262, 31501343] and the China Postdoctoral Science Foundation [2013M540169].

\section{References}

1. Munns R, Tester M (2008) Mechanisms of salinity tolerance. Ann Rev Plant Biol 59: 651-681.

2. Koyro HW (2006) Effect of salinity on growth, photosynthesis, water relations and solute composition of the potential cash crop halophyte Plantago coronopus (L). Environ Exper Botany 56(2): 136-146.

3. Glenn EP, Brown JJ, Blumwald EJ (1999) Salt tolerance and crop potential of halophytes Critical Review in Plant Science 18: 227-255.

4. Silveira JAG, Arajo SAM, Lima JPMS, Vigas RA (2009) Roots and leaves display contrasting osmotic adjustment mechanisms in response to $\mathrm{NaCl}$-salinity in Atriplex nummularia. Environmental Experimental Botany 66(1): 1-8.

5. Zhu JK (2001) Plant salt tolerance. Trends in Plant Science 6(2): 66-71.

6. Apse MP, Blumwald E (2007) $\mathrm{Na}^{+}$transport in plants. FEBS Lett 581(12): 2247-2254.

7. Tester M, Davenport R (2003) $\mathrm{Na}^{+}$tolerance and $\mathrm{Na}^{+}$transport in higher plants. Ann Bot 91(5): 503-527. 
8. Volkmar KM, Hu Y, Steppuhn H (1998) Physiological responses of plants to salinity: a review. Canadian Journal of Plant Science 78(1): 19-27.

9. Neocleous D, Vasilakakis $\mathrm{M}$ (2007) Effects of $\mathrm{NaCl}$ stress on red raspberry (Rubus idaeus L Autumn Bliss). Scientia Horticulture 112(3): 282-289.

10. Greenway H, Munns R (1980) Mechanisms of salt tolerance in nonhalophytes. Ann Rev Plant Physiol 31: 149-190.

11. Flowers TJ, Hajibagheri MA, Yeo AR (1991) Ion accumulation in the cell walls of rice plants growing under saline conditions: evidence for the Oertti hypothesis Plant Cell and Environment 14(3): 319-325.

12. Pérez López U, Robredo A, Lacuesta M, Sgherri C, Muňoz Rueda A, et al. (2009) The oxidative stress caused by salinity in two barely cultivars is mitigated by elevated $\mathrm{CO}_{2}$. Plant physiology 135(1): 29-42.

13. Martinez JP, Kinet JM, Bajji M, Lutts S (2005) NaCl alleviates polyethylene glycolinduced water stress in the halophyte species Atriplex halimus L. J Exp Bot 56(419): 2421-2431.

14. Zhou Q Yu BJ (2009) Accumulation of inorganic and organic osmolytes and their role in osmotic adjustment in $\mathrm{NaCl}$-stressed vetiver grass seedlings. Russian J Plant Physiol 56(5): 678-685.

15. Richards RA (1983) Should Selection for Yield in Saline Regions Be Made on Saline or Non-Saline Soils? Euphytica 32(2): 431-438.

16. Qidar M, Shams M (1997) Some agronomic and physiological aspects of salt tolerance in cotton (Gossypium hirsutum L). J Agronomy Crop Sci 179(2): 101-106

17. Ashraf M, Ahmad S (2000) Influence of sodium chloride on ion accumulation, yield components and fibre characteristics in salt-tolerant and salt-sensitive lines of cotton (Gossypium hirsutum L). Field Crops Res 66(2): 115-127.

18. Meloni DA, Oliva MA, Martinez CA, Cambraia J (2003) Photosynthesis and activity of superoxide dismutase, peroxidase and glutathione reductase in cotton under salt stress. Environmental sExperimental Botany 49(1): 69-76.

19. Bates LS, Waldren RP, Teare ID (1973) Rapid determination of free proline for water-stress studies. Plant and Soil 39(1): 205-207.

20. Mukherjee SP, Choudhuri MA (1983) Implications of water stress induced changes in the levels of endogenous ascorbic acid and hydrogen peroxide in Vigna seedlings. Plant Physiology 58: 166-170.

21. Bartolozzi F, Bertazza G, Bassi D, Cristoferi G (1997) Simultaneous determination of soluble sugars and organic acids as their trimethylsilyl derivatives in apricot fruits by gas-liquid chromatography. J Chromatogr 758(1): 99-107.

22. Zheng Y, Wang Z, Sun X, Jia A, Jiang G (2008) Higher salinity tolerance cultivars of winter wheat relieved senescence at reproductive stage. Environ Exp Bot 62(2): 129-138.

23. Ashraf M, Orooj A (2006) Salt stress effects on growth, ion accumulation and seed oil concentration in an arid zone traditional medicinal plant ajwain (Trachyspermum ammi [L] Sprague). J Arid Environ 64(2): 209220.

24. Liu J, Gu WQ, Shi, DC (2010) Seed germination, seedling survival and physiological response of sunflowers under saline and alkaline conditions. Photosynthetica 48: 278-286.

25. Noreen Z, Ashraf M and Akram N (2010) Salt-Induced Regulation of Some Key Antioxidant Enzymes and Physio-Biochemical Phenomena in Five Diverse Cultivars of Turnip (Brassica rapa L). J Agronomy and Crop Science 196: 273-285.

26. Berstein L, Ogata G (1966) Effects of Salinity on Nodulation, Nitrogen Fixation and Growth of Soybean and Alfalfa. Agron J 58(2): 201-203.
27. Gorham J, Jones RW, McDonnell E (1985) Some mechanisms of salt tolerance in crop plants. Plant Soil 89(1-3): 15-40.

28. Silveira JAG, Viègas RdA, Rocha IMAd, Moreira ACdOM, Moreira RdA (2003) Proline accumulation and glutamine synthetase activity are increased by salt-induced proteolysis in cashew leaves. J Plant Physiol $160(2): 115-123$.

29. Zhong H, Läuchli A (1994) Spatial distribution of solutes, K, Na, Ca and their deposition rates in the growth zone of primary cotton roots: Effects of $\mathrm{NaCl}$ and $\mathrm{CaCl}_{2}$. Planta 194(1): 34-41.

30. Aslam M, Qureshi RH, Ahmed N, Kausar MA (1991) Relative growth rate and ion transport in rice grown under saline environment. Pakistan J Botany 23: 3-11.

31. Mišić D, Šiler B, Nestorović Živković J, Simonović A, Maksimović V, et al. (2012) Contribution of inorganic cations and organic compounds to osmotic adjustment in root cultures of two Centaurium species differing in tolerance to salt stress. Plant Cell, Tissue Organ Culture (PCTOC) 108: 389-400.

32. Lacerda CFD, Cambraia J, Cano MAO, Ruiz HA (2001) Plant growth and solute accumulation and distribution in two sorghum genotypes, under $\mathrm{NaCl}$ stress. Revista Brasileira de Fisiologia Vegetal 13: 270-284.

33. Silveira JAG, Araujo SAM, Lima JPMS, Viegas RA (2009b) Roots and leaves display contrasting osmotic adjustment mechanisms in response to $\mathrm{NaCl}$-salinity in Atriplex nummularia Environmental and Experimental Botany 66(1): 1-8.

34. Hassine AB, Lutts S (2010) Differential responses of saltbush Atriplex halimus L exposed to salinity and water stress in relation to senescing hormones abscisic acid and ethylene. J Plant Physiol 167(17): 14481456.

35. Lokhande VH, Nikam TD, Penna S (2010) Biochemical, physiological and growth changes in response to salinity in callus cultures of Sesuvium portulacastrum L. Plant Cell Tissue Organ Culture 102(1): 17-25.

36. Lutts S, Kinet JM, Bouharmont J (1996) Effects of salt stress on growth mineral nutrition and proline accumulation in relation to osmotic adjustment in rice (Oryza sativa L) cultivars differing in salinity resistance. Plant Growth Regulation 19(3): 207-218.

37. Munns R (2002) Comparative physiology of salt and water stress. Plant Cell Environ 25(2): 239-250.

38. Maali B, Kilani Ben R, Dorsaf M, Amira BenMna, Kamel H, et al. (2014) Effect of high salinity on Atriplex portulacoides: Growth, leaf water relations and solute accumulation in relation with osmotic adjustment. South African J Botany 95: 70-77.

39. Gorham J (1994) Salt tolerance in the Triticeae: K/Na discrimination in some perennial wheatgrasses and their amphiploids with wheat. J Exp Bot 45(4): 441-447.

40. Greenway H, Munns R (1983) Interactions between growth, uptake of $\mathrm{Cl}^{-}$and $\mathrm{Na}^{+}$and water relations of plant in saline environments II Highly vacuolated cells. Plant Cell Environ 6(7): 675-689.

41. Koyro HW (2006) Effect of salinity on growth, photosynthesis, water relations and solute composition of the potential cash crop halophyte Plantago coronopus (L). Environ Exper Botany 56(2): 136-146.

42. Munns R (2002) Comparative physiology of salt and water stress. Plant Cell Environ 25(2): 239-250.

43. Nobel PS (1991) Physicochemical and environmental plant physiology. Academic Press, USA, pp. 635 
ISSN: 2574-1241

DOI: 10.26717/BJSTR.2019.15.002679

Lei Zhang. Biomed J Sci \& Tech Res

(c) (P) This work is licensed under Creative

Submission Link: https://biomedres.us/submit-manuscript.php

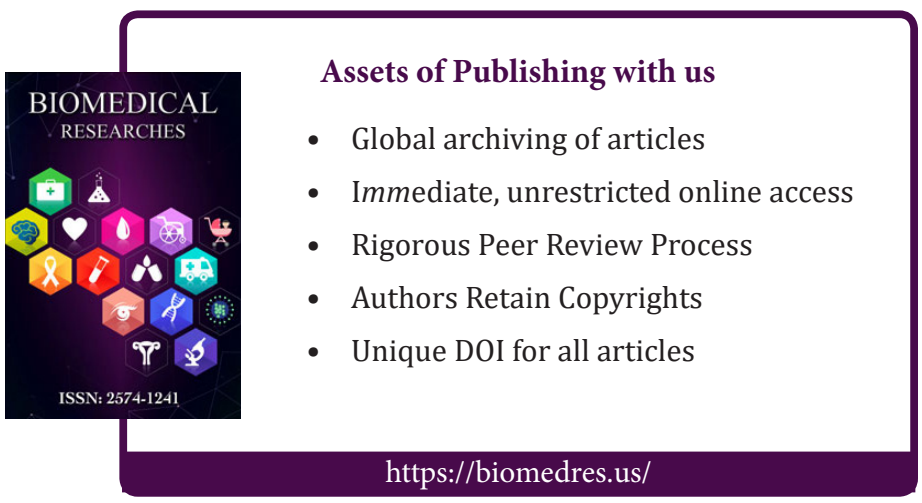

